Qi-han XU*

\title{
Description of the final stadium larva of Calicnemia sinensis Lieft- inck, with discussion of the larval characters of genus Calicnemia Strand (Odonata: Zygoptera: Platycnemididae)
}

\author{
https://doi.org/10.23797/2159-6719_24_4
}

Received: 18 September 2020 - Accepted: 21 October 2020 - Published: 8 July 2021

\begin{abstract}
The final stadium larva of Calicnemia sinensis Lieftinck is described and illustrated in detail. It is characterized by (1) palpal lobe of prementum with two end hooks of unequal size, the inner longer and sharper, and the outer shorter and stouter; (2) inner side of palpal lobe with five long setae above and two or three short ones below; (3) wing sheaths parallel to each other, reaching beyond the distal margin of abdominal segment 6; and (4) caudal gills strongly ridged, median gill large and broad, more than 2 times of lateral gill in width.
\end{abstract}

Keywords: Odonata, dragonfly, diagnostic characters

\section{Introduction}

The genus Calicnemia Strand, 1928 contains over 20 species, distributed in tropical and subtropical Asia (Zhang, 2019). To date, little is known about the larval stages of the genus. The first description of a Calicnemia larva was from Kumar \& Prasad (1977), they described a larva from Dehra Dun valley (India) as C. miles (Laidlaw, 1917), but unfortunately it was misidentified and Lieftinck (1984) corrected it to be C. eximia (Selys, 1863). He also provided detailed description and figures of the larva of C. miniata (Selys, 1886) at the same time (Lieftinck, 1984). Afterwards, the larval appearance of $C$. sinensis has been described very briefly, with a habitus photo by Tam et al. (2011). Recently, Dawn (2019) redescribed the larva of $C$. eximia in detail and compared it with the larva of $C$. miniata, then Chen \& Yu (2020) described that of C. gulinensis Yu \& Bu, 2008 and discussed briefly the important morphological characters of the caudal gills and the possible functional adaptation. During field work in Nanjing County, southern Fujian in 2020, three final stadium larvae of C. sinensis were collected. One of the larvae was reared in laboratory, and its identification was confirmed by the adult that emerged. Here, the final stadium larva of $C$. sinensis is described and illustrated in detail, and, after comparison with morphological characters of the three known Calicnemia larvae, diagnostic characters of the larvae of genus Calicnemia Strand are discussed and summarized. In the following description, mandibular terminology and formula follow Watson (1956), and S1-10 = abdominal segments $1-10$.

\section{Description of the final stadium larva of Calicnemia sinensis Lieftinck, 1984}

\section{Specimens studied}

Two male larvae and one female larva, the larvae were collected from Nanjing County ( $\left.24^{\circ} 38^{\prime} \mathrm{N}, 117^{\circ} 11^{\prime} \mathrm{E}\right)$, southern Fujian by Qi-han Xu on 22 March 2020. Specimens are deposited in Department of Garden and Horticulture, Zhangzhou City University, Fujian, China. 


\section{Description}

The larva with large head, parallel wing sheaths, relatively large and strongly ridged median gill. General appearance and colour pattern as shown in Figure 1.

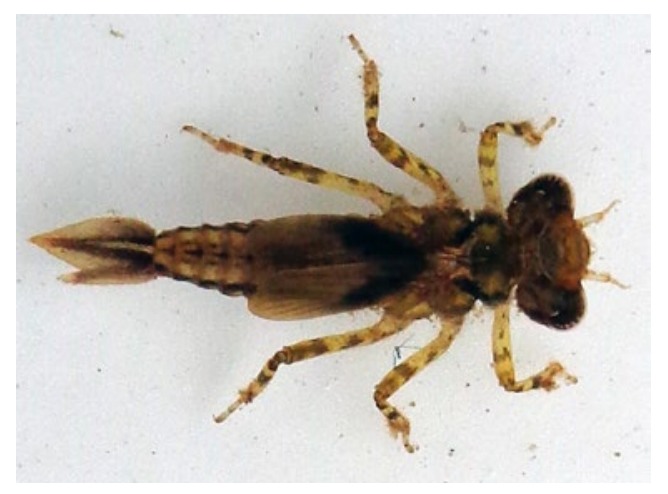

Figure 1. Final stadium larva of Calicnemia sinensis: habitus, dorsal view.

Head. Large, wider than long, flat dorsally. Compound eyes large, protruding laterally. Postocular lobe roughly rounded. Occipital margin arched inwards. Antenna (Figure 2a) six segmented, second one being the longest. Head and antennae fringed with numerous hairs. Prementum (Figures $2 \mathrm{~b}, 2 \mathrm{c})$ a trifle longer than wide, spatulate, with a pair of premental setae, four distinct spines near the articulation of the palpal lobes, a row of robust spines on distal half of both lateral margins, and a cluster of small spines on both lateral areas below; median lobe very prominent, arched strongly forward, its anterior margin furnished with minute crenulations. Palpal lobe (Figures 2c, 2d) short, furnished with a row of spines on basic half of outer side, and with two end hooks of unequal size, the inner longer and sharper, and the outer shorter and stouter; inner side of palpal lobe with five long setae above and two or three short ones below. Movable hook gradually bent inward, without any additional spine on it. Mandibles (Figure 2e, 2f) with four prominent incisors forwardly arranged in a row, and an additional tooth situated below and laterally; and a pair of molars on both sides of the inside of left mandible, only one visible on right mandible. Thus, mandibular formula: L $1234 \mathrm{y} \mathrm{ab} / \mathrm{R} 1234 \mathrm{y}$ a; in left mandible, $2<1<3<4, \mathrm{~b}>\mathrm{a}$; and in right one, $1<2<3<4$.

Thorax. Markedly narrower than head. Wing sheaths parallel to each other, reaching beyond the distal margin of abdominal segment 6 . Legs (Figures $1,2 \mathrm{~g}$ ) with alternate pale and dark bands; each femur with sparse short spines on dorsal side; each tibia with dense long hairs on $1 / 3$ distal end, and a longitudinal row of several long spines on ventral side, a longitudinal strip of short spines on dorsal side of $1 / 3$ distal end, a cluster of robust spines on ventral side of very distal end, and row of robust spines circled on distal border of tibia; each tarsus covered with dense hairs, and bearing a pair of spines ventrally on the apical end.

Abdomen. Anterior segments wider and gradually narrowing towards end. Lateral edges of segments 2 to 7 bulging outward, 8 to 9 less bulging, 10 not bulging. Vestigial male primary genitalia (Figure 2i) situated on S9, paired, tubercle-shaped. Female primary genitalia (Figure $2 \mathrm{~h}$ ) arising from base of S9 and extending beyond distal margin of S10; primary lateral valvula with nippleshaped process at tip. Caudal gills (Figure 2i) strongly ridged, triradiate in transverse section, with very coarse mid-ribs; median gill large, leaf-shaped; lateral gill dagger-shaped, its width less than $1 / 2$ of median gill, and its length less than $3 / 4$ of median gill.

Measurements $(\mathrm{mm})$. Body length (including caudal gills) 13.5-13.7; maximum width of head 3.8-3.9; hind femur 3.0-3.1; hind-wing sheath 4.2-4.3; median gill 3.0-3.1; lateral gill 2.4-2.5. 

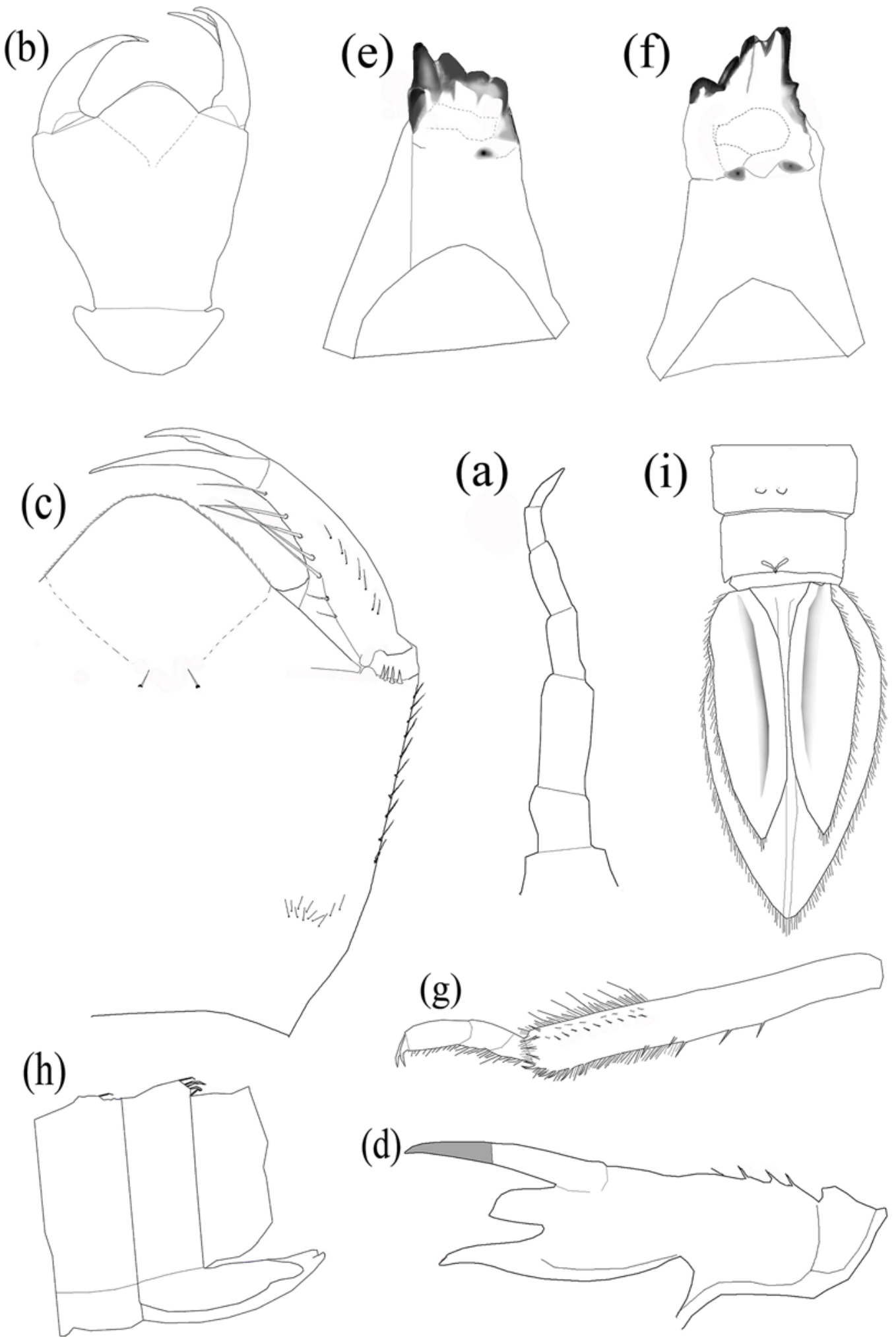

Figure 2. Morphological details of the final stadium larva of Calicnemia sinensis: (a) left antenna, dorsal view; (b) prementum, ventral view; (c) prementum, dorsal view; (d) palpal lobe, frontal view; (e) right mandible, inner side; (f) left mandible, inner side; (g) hind leg, inner side; (h) female primary genitalia, lateral view; (i) male distal abdomen, ventral view. 


\section{Differential diagnosis}

Among the four known Calicnemia larvae, that of $C$. sinensis can be easily distinguished in appearance from those of C. eximia, C. gulinensis and C. miniata by the large and broad median caudal gill, and the distinct body color pattern. In addition, the larva of $C$. sinensis can be separated from that of C. eximia by a pair of premental setae (no premental setae in C. eximia), inner side of palpal lobe with five long setae above and two or three short ones below (that with three distinct and one minute setae in $C$. eximia), and by legs coloured with dark bands (legs without prominent coloured bands in $C$. eximia); the larva of $C$. sinensis can also be separated from that of $C$. gulinensis by inner side of palpal lobe with five long setae above and two or three short ones below (that with two strong and three weak setae in C. gulinensis), antenna 6-segmented (antenna 7-segmented in C. gulinensis), and by legs coloured with dark bands (that lacking distinct bands or marks in C. gulinensis); the larva of C. sinensis can also be separated from that of C.miniata by inner side of palpal lobe with five long setae above and two or three short ones below [not the same in C.miniata in Kumar \& Prasad (1977), in Lieftinck (1984) and in Dawn (2019)], four distinct spines near the articulation of the palpal lobes (three distinct spines only in C.miniata), and by wing sheaths reaching beyond the distal margin of segment 6 (wing sheaths reaching the distal margin of segment 5 in C.miniata).

\section{Biological notes}

The larvae were found inhabiting wet moss beds on a rocky precipice with sprinkling water seeps in subtropical forest (Figure 3,4), and show adaptations for semi-terrestrial habitat in its compact form, dense body covering of spines and hairs, and strongly ridged caudal gills. The adults (Figure 5) first appear in Fujian in early April, and flying season ends at the end of May.

\section{Discussion of the taxonomic characters of the larvae of genus Calicnemia Strand}

After analysis of the common morphological characters of the known Calicnemia larvae (C. eximia, C. gulinensis, C. miniata and C. sinensis), the major taxonomic characters of the larvae of the genus can be tentatively summarized as follows: (1) small size with large head, dense body covering of spines and hairs; (2) median lobe of prementum arched strongly forward, its anterior margin furnished with minute crenulations; (3) palpal lobe of prementum with two end hooks of unequal size, the inner shorter and stouter, and the outer longer and sharper; its inner side with a row of setae; (4) wing sheaths parallel to each other; and (5) caudal gills saccoid, triradiate in transverse section. 


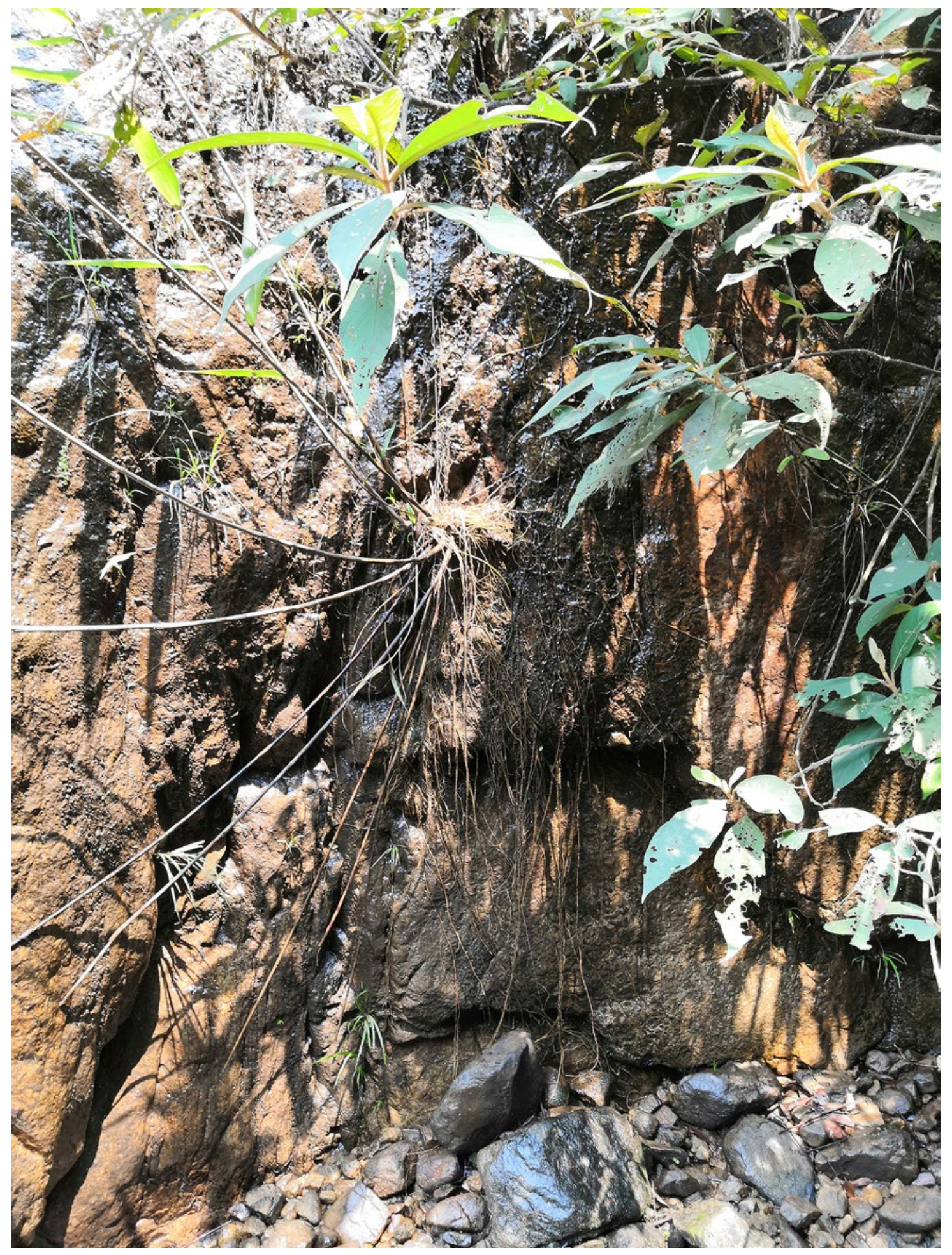

Figure 3. Habitat for Calicnemia sinensis larvae. 


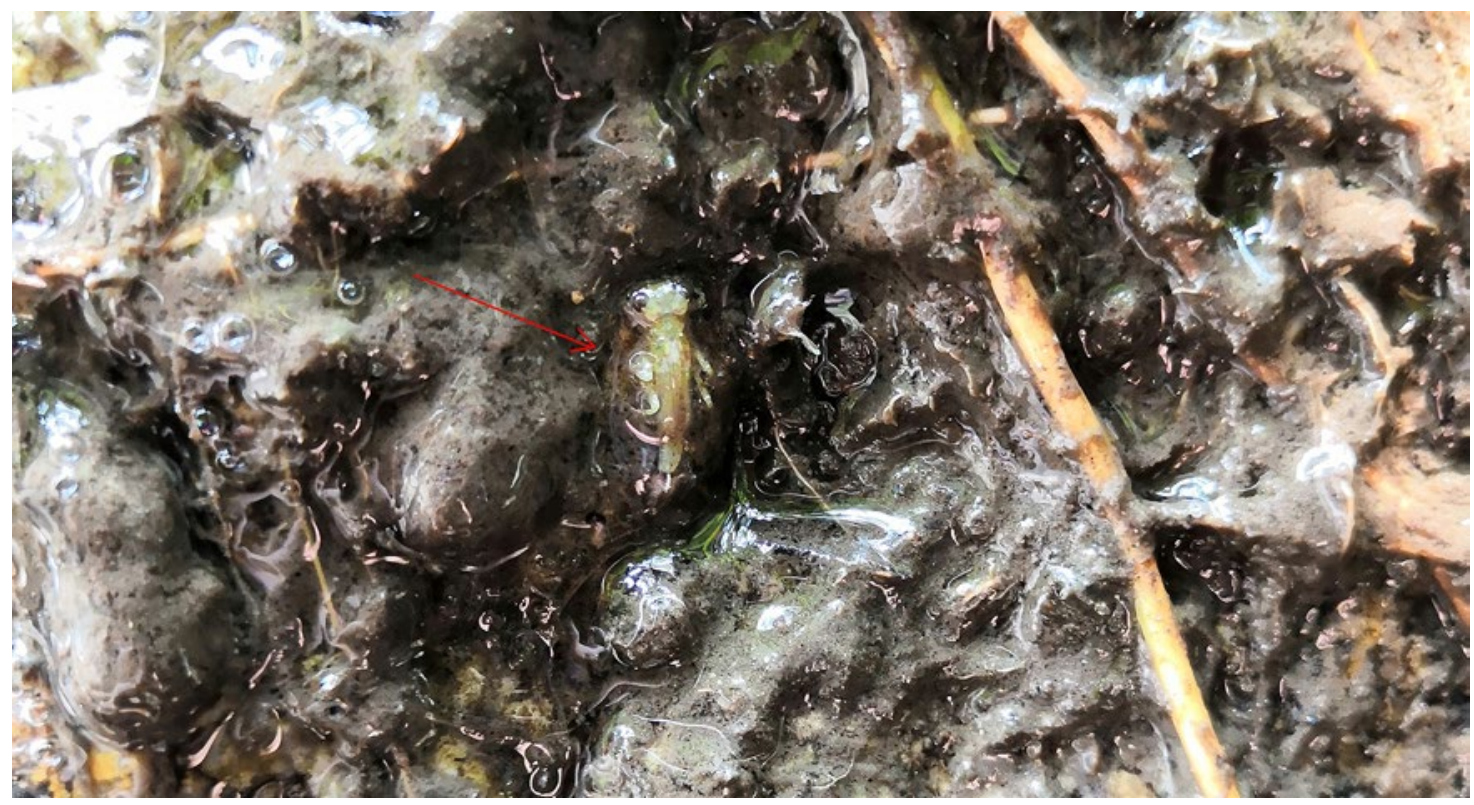

Figure 4. Larva of Calicnemis sinensis in situ inhabiting wet moss beds on a rocky precipice.

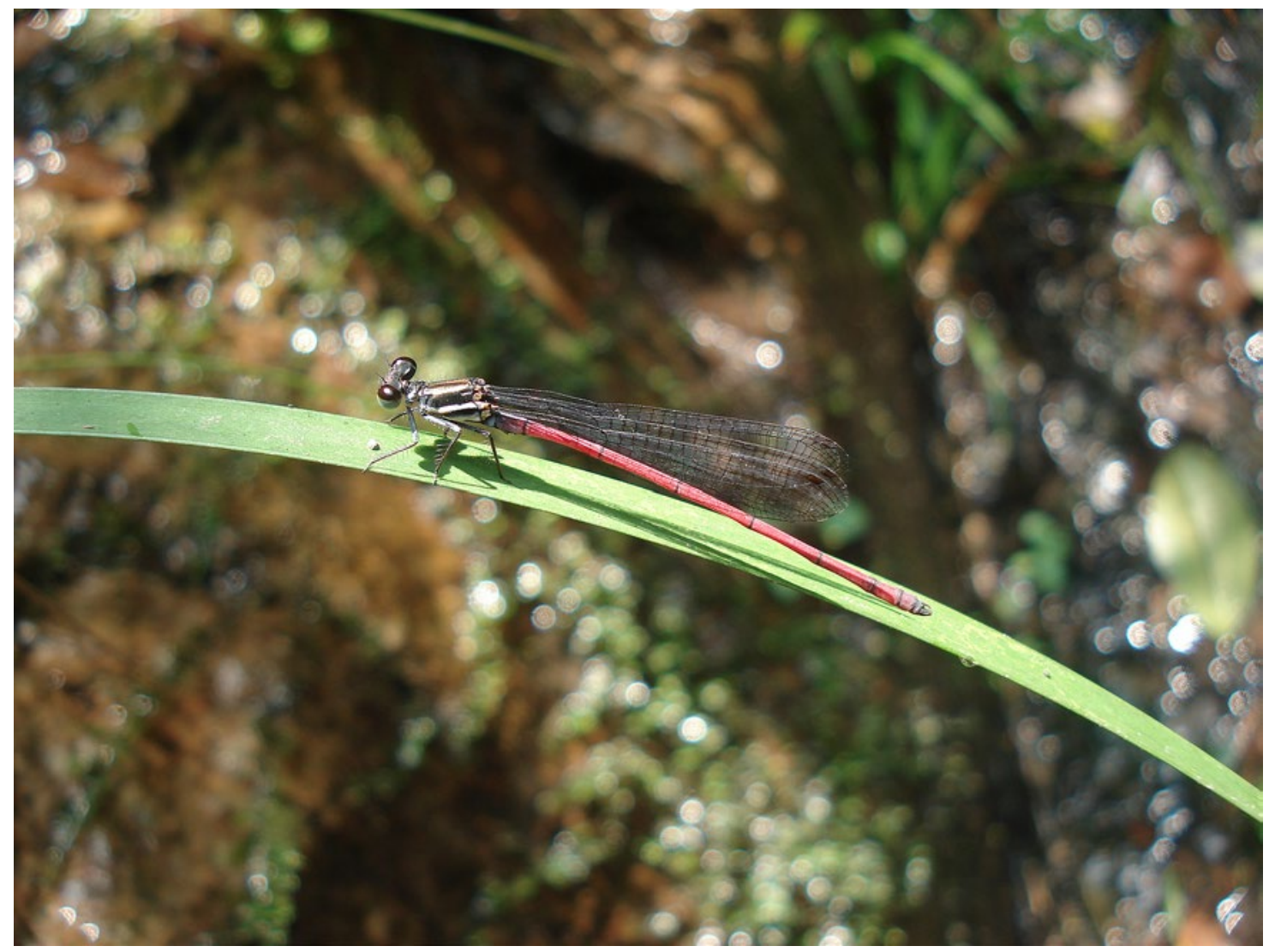

Figure 5. Calicnemia sinensis, male. 


\section{Acknowledgments}

I am grateful to Dr Martin Schorr, Dr Xin Yu, and Dr Prosenjit Dawn for their kind help in providing literature necessary for the present study, and thank reviewers and editor for their valuable remarks and suggestions.

\section{References}

Chen X. -y \& Yu, X. (2020). A description of the final stadium larva of Calicnemia gulinensis Yu \& $\mathrm{Bu}, 2008$ (Odonata: Platycnemididae). International Journal of Odonatology, 23, 191-197. https://doi.org/10.1080/13887890.2020.1760949

Dawn, P. (2019). Description of the last instar larva of Calicnemia eximia (Selys, 1863) (Odonata: latycnemididae) from West Bengal, India. Zootaxa, 4657, 183-187. https://doi.org/10.11646/zootaxa.4657.1.10

Kumar, A. \& Prasad, M. (1977). Last instar larvae of two Odonata species from Western Himalayas. Entomon, 2, 225-230.

Lieftinck, M.A. (1984). Further notes on the specific characters of Calicnemia Strand, with a key to the males and remarks on some larval forms (Zygoptera: Platycnemididae). Odonatologica, 13, 351-375. http://natuurtijdschriften.nl/record/591665

Tam, T.W., Leung, K.K., Kwan, B.S.P., Wu, K.K.Y., Tang, S.S.H., So, I.W.Y., Cheng, J.C.Y., Yuen, E.F.M., Tsang, Y.M., and Hui, W.L. (2011). The Hong Kong Dragonflies. Hong Kong: Agriculture, Fisheries and Conservation Department, Friends of Country Park and Cosmos Books Ltd.

Watson, M.C. (1956). The utilization of mandibular armature in taxonomic studies of anisopterous nymphs. Transactions of the American Entomological Society, 81, 155-202.

Zhang, H. -m. (2019). Dragonflies and Damselflies of China. Chongqing University Press, Chongqing, $12+1459 \mathrm{pp}$. 